\title{
Enhancing child survival by bridging the gaps in emergency paediatrics
}

\author{
Srilal de Silva ${ }^{1}$ \\ Sri Lanka Journal of Child Health, 2013; 42(3): 115-128
}

(Key words: Child survival; emergency paediatrics)

Firstly, let me thank the Sri Lanka College of Paediatricians (SLCP) for electing me as its $16^{\text {th }}$ President for the year 2013. I thank the immediate Past President, Professor Asvini Fernando and her Council and all Past Presidents for their excellent contribution to improve child health during their tenures. I hope I will be able to continue the good work to fulfil the aspirations of the membership.

My theme for this year is "Enhancing child survival by bridging the gaps in emergency paediatrics". During the Crimean War in 1853, Florence Nightingale managed to reduce the mortality rate among wounded soldiers from $40 \%$ to $2 \%$ by following a "critical care protocol". She also commented on the advantage of having a separate area in the hospital for patients recovering from surgery. Therefore as early as the $19^{\text {th }}$ century, the celebrated Nightingale practised the concept of emergency and critical care.

In 2001, as there were no Paediatric Intensivists at that time, I was appointed by the Ministry as the Paediatrician-in-Charge of the Paediatric Intensive Care Unit (PICU) in the premier children's hospital in the country. I was the first paediatrician to take up Paediatric Intensive Care as a full time vocation. While working in the unit, I noticed that most of the admissions were extremely ill and unstable children, many following cardiac arrests and secondary brain damage with multi-organ failure. It did not take too long for me to realize that there are two strategies to improve the outcome of these children. I was not sure which strategy should take priority.

1. Improve the standards of paediatric intensive care

2. Improve emergency care given to children before they get admitted to the PICU

${ }^{1}$ Consultant Paediatrician, Paediatric Intensive Care Unit, Lady Ridgeway Hospital for Children, Colombo

*Address given on induction as President SLCP, November 2012

As time passed, I realized the importance of giving more weightage to the second strategy. The emergency care given to children before they get admitted to the PICU is much more important to reduce the mortality and morbidity in our children and there are many more gaps to bridge in Paediatric Emergency Care to achieve this target.

Let me start by comparing the problems faced by children worldwide with the situation prevalent in Sri Lanka. In the world 1.2 billion people live on less than US\$ 1 a day ${ }^{1}$. In Sri Lanka $8.9 \%$ of the total population live on less than US\$ $1 /$ day $^{2}$. Worldwide, 2.4 billion lack adequate sanitation ${ }^{3}$. In Sri Lanka, $91 \%$ have improved sanitation facilities ${ }^{3}$. Worldwide, one billion people lack access to safe water ${ }^{3}$. In Sri Lanka, $90 \%$ of the population use improved drinking water ${ }^{3}$. In the world, 130 million children have no access to education ${ }^{1}$. In Sri Lanka, $6 \%$ of children between 5-17 years are not attending school ${ }^{4}$. Worldwide 350 million children work. ${ }^{1}$ In Sri Lanka, $12.9 \%$ of children, ages ranging from 5-17 years, work ${ }^{4}$. Globally 8.8 million children die per year, most deaths occurring in the continents of Asia and Africa $^{3}$. This is relatively more in Asia, because of the high density of population. According to the Registrar General Department in Sri Lanka, out of the total population of 20 million, the under 5 population is $9 \% 5$.

Let us consider the Millennium Development Goals (MDGs). "Are we achieving the targets or can we go beyond"? MDG goal number 4 is to reduce child mortality by two thirds from 1990 to 2015 . The indicators of MDG 4 are:

- Under 5 mortality rate,

- Infant mortality rate (IMR)

- Proportion of 1 year old children immunized against measles.

According to the Registrar General Department, the under 5 mortality was 22.2 in 1991 and 10.4 in 2007 per 1000 live births ${ }^{5}$. However, there is a discrepancy in these figures when compared with figures from the 
Family Health Bureau (FHB) and demographic health survey of $\mathrm{UNICEF}^{2,6}$. The UNICEF figures of 32 in 1990 and 17 in 2010 are much higher than the Registrar General and FHB figures ${ }^{5.6}$.

According to the country reported data of 2010, like most of the other countries in the region, Sri Lanka is on track to achieve MDG $4^{7,8}$. With the existing well established health infra-structure, we should aim to achieve the target much earlier than the other countries. Therefore, we need to identify the deficiencies and try to bridge the gaps.

In the world, over $40 \%$ of child deaths occur during the neonatal period ${ }^{1}$. Beyond the neonatal period, a significant number of deaths are due to diarrhoea, malaria, measles and HIV which is not the case in our country ${ }^{5}$.

According to the national statistics of Sri Lanka, 74\% under 5 deaths were due to neonatal deaths in $2011^{5}$. Most of the neonatal deaths were due to prematurity, birth asphyxia, surfactant deficiency and septicaemia which are on par with the world trend ${ }^{7}$. The causes of death in older children are congenital heart diseases, encephalitis, respiratory infections and septicaemia?
The same pattern is reflected in the institutional level data as well. For example, at Teaching Hospital Karapitiya, $63 \%$ of deaths under 5 years are neonatal deaths ${ }^{9}$. Therefore to achieve MDG-4 we have to concentrate more on neonatal deaths.

Today, wastage of a pregnancy is unacceptable. This is because

- The families are smaller, with declining population growth.

- $\quad$ Elderly mothers with late marriages

- Sub fertile mothers with IVF pregnancies and

- Improved obstetric quality care

Because of these, paediatricians who look after newborns are under tremendous pressure as the parents demand a healthy newborn with no disabilities, even irrespective of a stormy neonatal period. Surprisingly, there is a significant reduction in neonatal mortality, from 1945 to 2003 in spite of no neonatal intensive care units, no neonatologists and no ventilators available throughout the country Figure 1.

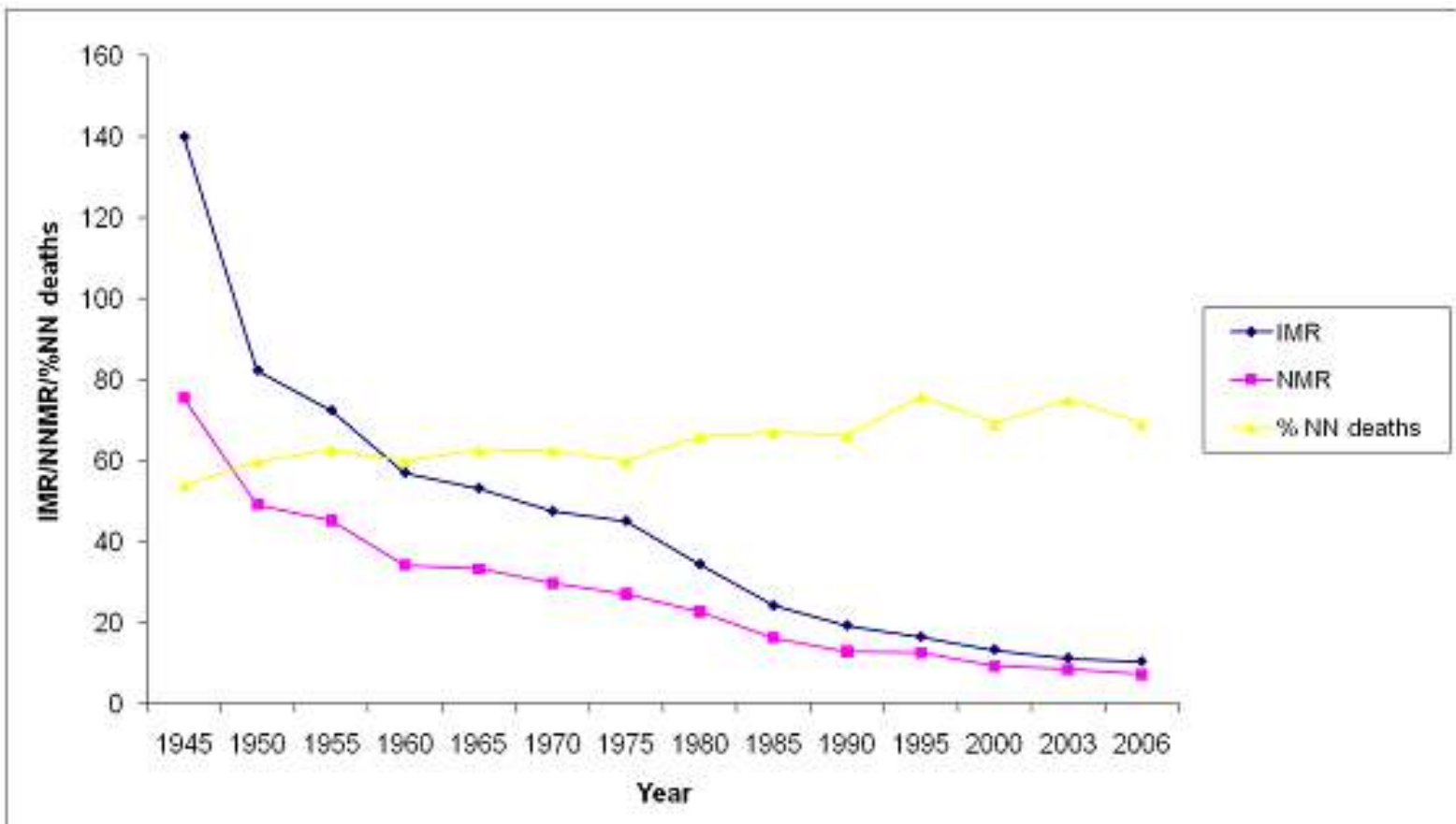

Figure 1: Trends in infant and neonatal mortality $1945-2006^{5}$

Possible reasons for this reduction are:

1. $98 \%$ deliveries occur in institutions, attended by skilled birth attendants.
2. High literacy rate of women and

3. Free access to health care delivery system 
However, since then, the neonatal mortality has been stagnant. The neonatal mortality rate (NMR) at present is $10 / 1000$ live births ${ }^{6}$. It is noteworthy that the percentage contributed by NMR for the infant mortality rate (IMR) has gone up, which indicates that we are still struggling to provide good quality neonatal care in the country ${ }^{5}$. It is obvious that if we need to reduce the under-5 year mortality, we need to invest on neonatal care.

In an article published in the Lancet in 2005, by Damstadt et al, 16 low cost evidence based interventions, which help to improve NMRs were highlighted $^{10}$. While some of them are the duties of obstetricians, the paediatricians need to address the resuscitation of newborn babies as an intra-partum strategy and the postnatal strategies are breastfeeding, prevention of hypothermia, kangaroo mother care and community based neonatal infection case management. These postnatal strategies are well tested and are taught in the 'Essential Newborn Care' module in Sri Lanka but unfortunately the effective practice of these strategies are not being audited in our country, especially in areas where there are high NMRs.

When I started working in the PICU at LRH in 2001, I received many asphyxiated babies for ventilation, from all over the country. Even though the majority went home alive, most of them ended up with severe disabilities. Hence, I realized that effective resuscitation at birth is much more important to reduce the asphyxia related morbidity and mortality. Introduction of Neonatal Life Support (NLS) module to this country in 2006, made a huge impact on the morbidity and mortality caused by birth asphyxia.

It is with a great sense of humility that I take credit for the introduction of this module to our country. This was made possible as a result of a discussion I had with Dr. Babu Kumararatne, Consultant Neonatologist at the Royal New Cross Hospital in Wolverhampton, UK. He promised to organize a faculty with the approval of the resuscitation council of the UK. My job was to organize funds from this end. When I was desperately looking for funds, it was Dr Anoma Jayathilake, who introduced me to the UNICEF and convinced the UNICEF to fund the project. Eighty doctors, including 60 Consultant Paediatricians, were trained by the NLS Faculty of the UK and they handed over all the teaching material, including the slides and scenarios, to conduct the follow up programmes locally. A year later, the local manual was written by the members of Sri Lanka College of Paediatricians, appointed under the Health Sector Development Project. The follow up programmes commenced in 2007. The manual was revised on several occasions and 2010 guidelines are included in the present manual. Up to date 125 workshops were conducted, and a total of nearly 3000 healthcare workers have been trained by the local faculty, under the patronage of the Perinatal Society of Sri Lanka (PNSL) and the Sri Lanka College of Paediatricians (Table 1).

Table 1

NLS training - follow up workshops

\begin{tabular}{|l|l|l|l|l|l|}
\hline & 2007 & 2008 & 2009 & 2011 & 2012 \\
\hline Doctors & 283 & 141 & 404 & 210 & 135 \\
\hline Nurses & 226 & 248 & 620 & 56 & 78 \\
\hline Midwives & 41 & 83 & 176 & 15 & 16 \\
\hline Total & 550 & 472 & 1200 & 281 & 229 \\
\hline \multicolumn{7}{|c|}{ Grand Total $=2732$} \\
\hline
\end{tabular}

We have covered almost all the districts in the country, including the North and the East (Figure 2).

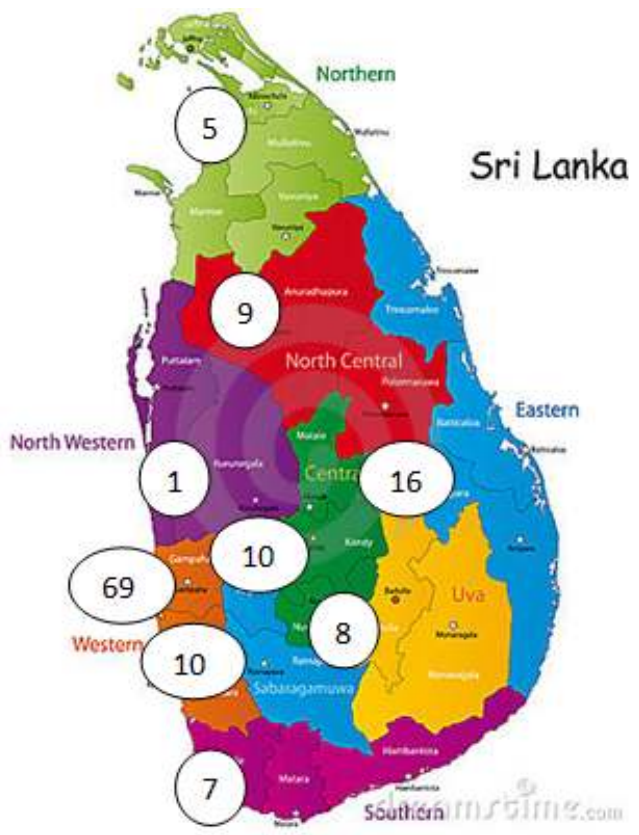

Figure 2: NLS programmes on provincial basis 2007-2012

The NLS course is a one day labour intensive workshop, needing 8 paediatricians as resource persons for 24 participants. The dedicated paediatricians, who were resource persons, spent a lot of time and energy in teaching, in spite of their busy schedules. It is most rewarding to see that deaths due to birth asphyxia were reduced in many hospitals like Mahamodara, Batticaloa, and Ragama after the introduction of NLS (tables 2-4). Training nurses and midwives on bag and mask ventilation has 
contributed to the improved statistics immensely, as these healthcare workers are physically present in the labour rooms throughout the day.

Table 2

NICU statistics, Teaching Hospital, Mahamodara

\begin{tabular}{|c|c|c|c|}
\hline Year & $\begin{array}{c}\text { Total } \\
\text { deliveries }\end{array}$ & $\begin{array}{c}\text { PBU } \\
\text { admissions }\end{array}$ & $\begin{array}{c}\text { Birth } \\
\text { asphyxia } \\
\text { deaths }\end{array}$ \\
\hline 2006 & 15991 & 1053 & 21 \\
\hline 2007 & 14704 & 979 & 13 \\
\hline 2008 & 14310 & 1048 & 15 \\
\hline 2009 & 12404 & 900 & 09 \\
\hline 2010 & 11681 & 857 & 07 \\
\hline 2011 & 12423 & 697 & 10 \\
\hline
\end{tabular}

Source-NICU register, $T$ H, Mahamodara

Table 3

NICU statistics, Teaching Hospital, Batticaloa

\begin{tabular}{|c|c|c|c|}
\hline Year & $\begin{array}{c}\text { Total } \\
\text { deliveries }\end{array}$ & $\begin{array}{c}\text { PBU } \\
\text { admissions }\end{array}$ & $\begin{array}{c}\text { Birth } \\
\text { asphyxia } \\
\text { deaths }\end{array}$ \\
\hline 2006 & 6322 & 1087 & 30 \\
\hline 2007 & 6521 & 1028 & 42 \\
\hline 2008 & 6945 & 1075 & 14 \\
\hline 2009 & 6532 & 1270 & 11 \\
\hline 2010 & 6935 & 1181 & 29 \\
\hline 2011 & 6393 & 1119 & 18 \\
\hline
\end{tabular}

Source-NICU register, $T$ H, Batticaloa

Table 4

NICU statistics, Teaching Hospital Ragama

\begin{tabular}{|c|c|c|c|}
\hline Year & $\begin{array}{c}\text { Total } \\
\text { deliveries }\end{array}$ & $\begin{array}{c}\text { PBU } \\
\text { admissions }\end{array}$ & $\begin{array}{c}\text { Birth } \\
\text { asphyxia } \\
\text { deaths }\end{array}$ \\
\hline 2006 & 6396 & 544 & 10 \\
\hline 2007 & 5643 & 445 & 4 \\
\hline 2008 & 6075 & 436 & 4 \\
\hline 2009 & 5951 & 360 & 7 \\
\hline 2010 & 6312 & 382 & 3 \\
\hline 2011 & 6122 & 394 & 1 \\
\hline
\end{tabular}

Source-NICU register, TH, Ragama

Prematurity is a major contributor to neonatal mortality. The low birth weight (LBW) rate in Sri Lanka was 16.7 in 2006/2007 ${ }^{2}$. Reduction of low birth weight is a challenge to the public health authorities.

In 1963, US first Lady Jacqueline Kennedy was hospitalized in her $34^{\text {th }}$ week of pregnancy. She underwent a caesarean section for fetal distress. Patrick Kennedy was born weighing 4 pounds. After the delivery, the baby developed RDS and was treated at Children's Hospital Boston. The baby died two days later. Patrick Kennedy's obituary in the New York Times stated that "the only treatment for a victim of hyaline membrane disease is to monitor the infant's blood chemistry and to try to keep it near normal levels. Thus, the battle for Kennedy baby was lost, only because medical science had not yet advanced far enough, to accomplish as quickly as necessary, what the body can do by itself in its own time".

Since the bulk of neonatal deaths are due to prematurity, it is vital to address this issue adequately. While good antenatal care, including antenatal steroids are in the hands of obstetricians, the paediatricians should take up the challenge of improving care provided for the pre-term babies.

Surfactant therapy is extremely important, to buy time till the lungs mature in pre-term babies with respiratory distress syndrome. Since it is an expensive drug, it took some time to convince the Ministry of Health to get surfactant to our hospitals. Prof Sujeewa Amarasena, the then President of the Perinatal Society of Sri Lanka, worked very hard with me, to make surfactant available to the government hospitals. Finally, we managed to get it in 2008. Since its introduction in 2008, surfactant use by the state hospitals has gone up remarkably. Inefficiency of getting the surfactant returns has lost the opportunity to audit the effect of this wonder drug on preterm survival.

Miranda Mugford in her article in Archives of Diseases in Childhood in 1991 stated that prophylactic surfactant therapy for all babies, less than 35 weeks gestation, the cost per survivors would be reduced by $5 \%$, and surfactant prophylaxis for all babies less than 31 weeks gestation, the cost per survivors would be reduced by $16 \%{ }^{11}$. Further, Tubman et al showed that if the cost per quality adjusted life year is considered, the surfactant therapy cost much less, compared with other interventions like renal transplantation, coronary bypass and haemodialysis ${ }^{12}$ (Table 5).

Table 5 : Cost of surfactant replacement therapy

\begin{tabular}{|l|c|}
\hline \multicolumn{1}{|c|}{ Treatment } & $\begin{array}{c}\text { Cost/Quality } \\
\text { adjusted life year }\end{array}$ \\
\hline Surfactant replacement & 710 \\
\hline Renal Transplantation & 1400 \\
\hline $\begin{array}{l}\text { Single vessel coronary artery } \\
\text { bypass drafting }\end{array}$ & 6000 \\
\hline Haemodialysis in hospital & 9000 \\
\hline
\end{tabular}

Source -Tubman et al BMJ Volume $30113^{\text {th }}$ Oct 1990 
CPAP is a non-invasive type of ventilation, which reduces the need for mechanical ventilation by $50 \%$. Even though, a few CPAP machines were available from 2006, there was no structured programme to educate healthcare workers on the use of CPAP ventilation. With the help of Prof Ashok Deorari, Professor of Neonatology of All India Institute of Medical Sciences, Delhi, India, I was instrumental in introducing CPAP ventilation module to our country through the Perinatal Society of Sri Lanka. He conducted 4 training programmes, in Colombo and Kandy in 2009, 2010 and 2011. Nearly 180 doctors and nurses were trained by these workshops. I am very grateful to the UNICEF for sponsoring these workshops.
Mechanical ventilation is the last option available to rescue these preterm babies. The life of Patrick Kennedy was lost because this facility was not available at that time to normalize the blood chemistry. In Sri Lanka, newborn ventilation was first started in 1985 by Dr. D.A. Sonnadara at LRH Paediatric ICU and at Sri Jayawardenapura Neonatal ICU. Before that, the newborns were sent for ventilation to the adult ICU of Colombo General Hospital, managed by Dr. Thistle Jayawardena. At present, newborns are being ventilated in NICUs all over the country. If we consider the outcome of the ventilated babies in different units in our country, in 2007, except in one unit, the survival rates of ventilated babies were less than 50\% (table 6).

Table 6: Outcome of neonatal ventilation in selected institutions from February-April, 2007

\begin{tabular}{|c|c|c|c|c|}
\hline Institution & No. ventilated & No. discharged & No. of deaths & No. transferred out \\
\hline Institution -8 & 4 & $1(25 \%)$ & $3(75 \%)$ & 0 \\
\hline Institution -2 & 29 & $9(31 \%)$ & $19(65.5 \%)$ & 1 \\
\hline Institution -5 & 20 & $7(35 \%)$ & $13(65 \%)$ & 0 \\
\hline Institution -7 & 21 & $7(33.3 \%)$ & $12(57.1 \%)$ & 0 \\
\hline Institution -3 & 2 & $1(50 \%)$ & $1(50 \%)$ & 3 \\
\hline Institution -1 & 31 & $14(45.2 \%)$ & $14(45.2 \%)$ & 7 \\
\hline Institution -4 & 24 & $8(33.3 \%)$ & $9(37.5 \%)$ & 2 \\
\hline Institution -6 & 44 & $35(79.5 \%)$ & $7(15.9 \%)$ & \\
\hline
\end{tabular}

The poor outcome of ventilated babies in the NICUs was due to inadequate training of healthcare persons in the management of ventilated babies. To bridge the gaps of knowledge in mechanical ventilation, with the help of Prof Ashok Deorari, Professor of Neonatology AIIMS, Delhi, I managed to introduce a 4 day Advanced Neonatal Ventilation module to this country in 2008. This was organized through the PSSL. Sixty doctors were trained. I have to thank the UNICEF for sponsoring this workshop. Subsequent to this stimulating workshop, there was a lot of interest among the neonatal caregivers on neonatal ventilation. We conducted two further workshops on ventilation in 2011 and 2012 by the local faculty. All these were well attended and greatly valued by the participants. There are problems pertaining to neonatal ventilation and CPAP ventilation, which have to be addressed. As the distributions of the machines is not on par with the number of deliveries, the mechanical ventilators and CPAP machines available in the centres, are not enough to cope up with the demand (tables 7).

In addition, in some centres, the available ventilators are being utilized $100 \%$ while in other centres, these are under-utilized. There were instances where Technical Evaluation Committees were not appointed when procuring the equipment. There are many machines without service contracts, because of lack of funds. This obviously adversely affects good quality ventilation. 
Table 9: Equipment available in different neonatal units

\begin{tabular}{|c|c|c|c|c|c|c|c|c|c|c|c|c|c|c|}
\hline 2011 & خे & 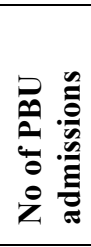 & 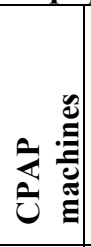 & 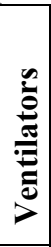 & 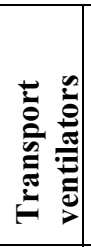 & 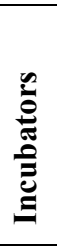 & 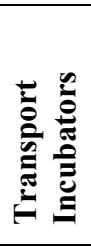 & 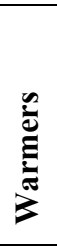 & 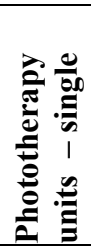 & 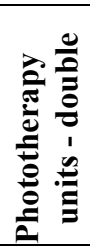 & 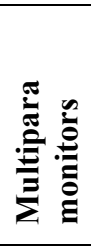 & 龸 & 总 & 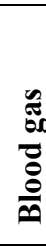 \\
\hline Castle Street & 16,285 & 2,997 & 3 & 4 & 0 & 12 & 1 & 7 & 18 & 1 & 3 & 6 & 22 & 0 \\
\hline Kurunegala & 13,272 & 426 & 1 & 5 & 0 & 14 & 0 & 2 & 5 & & 2 & 4 & 13 & 1 \\
\hline Mahamodara & 12,423 & 697 & 5 & 7 & 0 & 13 & 1 & 3 & 3 & 2 & 3 & 8 & 15 & 1 \\
\hline Anuradhapura & 11,194 & 1894 & 1 & 7 & 1 & 11 & 1 & 7 & 8 & 1 & 6 & 3 & 12 & 0 \\
\hline Kandy & 11,091 & 1696 & 3 & 3 & 0 & 16 & 1 & 5 & 14 & 2 & 6 & 9 & 20 & 1 \\
\hline Matara & 10,907 & 2341 & 1 & 3 & 0 & 9 & 1 & 6 & 7 & 4 & 3 & 7 & 11 & 1 \\
\hline Ratnapura & 9,512 & 1881 & 2 & 4 & & 11 & 2 & 3 & 11 & 2 & 6 & 8 & 18 & 1 \\
\hline Kalutara & 8,611 & 1261 & 2 & 3 & 0 & 13 & 0 & 2 & 13 & 0 & 2 & 6 & 15 & 0 \\
\hline Jaffna & 8,524 & 1430 & 2 & 2 & 0 & 10 & 0 & 4 & 8 & 2 & 2 & 4 & 6 & 0 \\
\hline Badulla & 7,927 & 1663 & 0 & 4 & 0 & 9 & 2 & 9 & 7 & 4 & 7 & 2 & 19 & 1 \\
\hline Peradeniya & 7,654 & 955 & 2 & 3 & 0 & 5 & 1 & 5 & & & 1 & 10 & 15 & 1 \\
\hline Batticaloa & 6,393 & 1119 & 1 & 2 & 0 & 8 & 0 & 8 & 6 & 2 & 2 & 2 & 6 & 0 \\
\hline Ragama & 6,122 & 394 & 2 & 3 & & 6 & 1 & 2 & 2 & & 3 & 1 & 9 & 1 \\
\hline Matale & 5,956 & 140 & 1 & 2 & & 12 & & 1 & 7 & & & 2 & 3 & \\
\hline Gampaha & 5,475 & 628 & 0 & 2 & & 5 & 1 & & 5 & & 1 & 4 & 12 & 1 \\
\hline Chilaw & 5,126 & 965 & 1 & 2 & & 7 & & & 3 & & & 4 & 8 & \\
\hline Kethumathi & 4,111 & 1065 & 1 & 2 & & 7 & 0 & & 9 & & & 5 & 8 & 1 \\
\hline Trincomalee & 3,908 & 459 & 2 & 4 & 2 & 12 & 1 & 2 & 6 & 0 & 6 & 2 & 7 & 1 \\
\hline Ampara & 3,880 & 618 & 1 & 5 & 0 & 4 & 2 & 2 & 8 & 0 & 1 & 2 & 11 & 0 \\
\hline Horana & 3,534 & 718 & 0 & 1 & 1 & 5 & 2 & 2 & 4 & 0 & 2 & 0 & 2 & 0 \\
\hline Diyatalawa & 3,009 & 426 & 2 & 2 & & 6 & 1 & 4 & 4 & & 1 & 2 & 8 & 1 \\
\hline Karapitiya & 0000 & 216 & 2 & 7 & 0 & 6 & 0 & 5 & 3 & 0 & 9 & 3 & 11 & 1 \\
\hline LRH & 0000 & 400 & 1 & 5 & & 10 & & 4 & 6 & 3 & 7 & 0 & 19 & 1 \\
\hline SBTH & 0000 & 400 & 1 & 5 & 1 & 19 & 1 & 6 & 9 & 0 & 6 & 2 & 12 & 0 \\
\hline
\end{tabular}

At present, we have 5 full time board certified neonatologists working in different parts of the country and another eleven paediatricians who are doing full time neonatal work. It is the responsibility of these neonatologists to introduce hi-tech measures such as high humidity incubators, umbilical arterial catheter (UAC) and umbilical venous catheter (UVC) access, peripheral arterial lines and arterial blood gas (ABG) monitoring, long lines, total parenteral nutrition (TPN), bleeding techniques, and skilled nursing to improve preterm care.

Neonatal sepsis occurs to a various degree in different units in the country. This preventable cause is a major contributor to morbidity and mortality among newborns. I have organized 4 workshops for doctors and nurses on the prevention of neonatal sepsis under the patronage of the perinatal society.

Lady Ridgeway Hospital (LRH) was the only paediatric hospital in the country, till Sirimavo Bandaranaike Children's Hospital was opened in Peradeniya, in 2007. LRH caters to the Western province, which has a population of 5.6 million, contributing to $28.2 \%$ of the total population in Sri
Lanka. LRH Medical Intensive Care Unit (MICU) has about 600 admissions per year. We have analyzed the percentage of deaths in children with different diseases admitted to the MICU. As you can see 50\% of children admitted to the PICU with septicaemia died in 2011 , and $33 \%$ of children with CHD, $28 \%$ of children with meningo-encephalitis, $27 \%$ of children with pneumonia have died. However, the death percentage in DHF was only $14 \%$. Most of these children admitted to our unit had late complications of the primary disease for a number of reasons. Therefore, it is important to optimize the management of ill children in a structured manner, from the time these children are admitted to hospital.

I am happy to state that our dengue survival has improved after the training we have had in Thailand in 2010, which was organized by the Epidemiology unit. I was fortunate to be one of the trainees in that group. This was further strengthened by the series of workshops conducted by the Thai experts in Sri Lanka in 2011, under the leadership of Prof. Deepthi Samarage the President of the SLCP at that time. LRH PICU receives extremely ill dengue children who have gone into shock more than once, very often 
with more than one organ failure. It is interesting to note that, there is not only improved survival but also a reduction in the requirement of ventilation and peritoneal dialysis after 2010, reflecting less fluid overload problem on admission (table 10). This is obviously the result of application of the new knowledge by our Paediatricians which was given by the Thai experts.

Table 10: Dengue statistics - LRH MICU

\begin{tabular}{|l|c|c|c|c|c|c|}
\hline & $\mathbf{2 0 0 7}$ & $\mathbf{2 0 0 8}$ & $\mathbf{2 0 0 9}$ & $\mathbf{2 0 1 0}$ & $\mathbf{2 0 1 1}$ & $\mathbf{2 0 1 2}$ \\
\hline Total admission & 6 & 14 & 198 & 161 & 136 & 80 \\
\hline LRH & 6 & 14 & 162 & 140 & 118 & 51 \\
\hline Outside & 0 & 0 & 36 & 21 & 18 & 29 \\
\hline Survived & $5(83 \%)$ & $12(85 \%)$ & $168(82 \%)$ & $136(85 \%)$ & $118(87 \%)$ & $71(88 \%)$ \\
\hline PD Inserted & & & $61(30 \%)$ & $37(30 \%)$ & $11(8 \%)$ & 0 \\
\hline
\end{tabular}

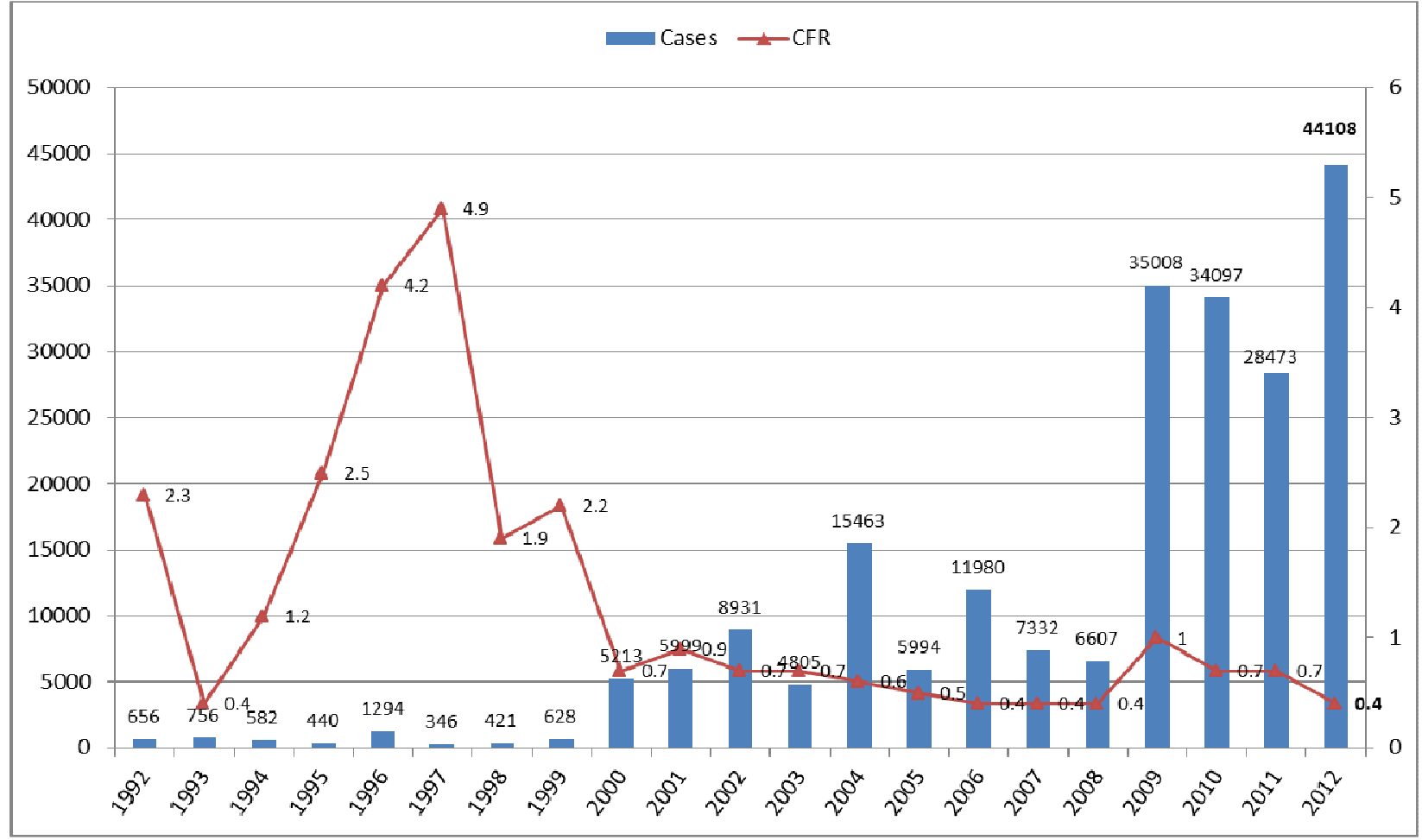

Figure 3: Case-fatality rate of dengue cases in children

Source, Epidemiology Unit, Ministry of Health

If we look at the national statistics of dengue deaths, it is evident that case fatality rate (CFR) of paediatric patients has reduced from 2010 onwards (Figure 3). I am glad to say that there is a marked improvement in the management of dengue in the paediatric age group $^{13}$ (Figure 4). The rational application of simple principles, according to the patho-physiology of dengue, has improved the outcome of paediatric dengue patients. 


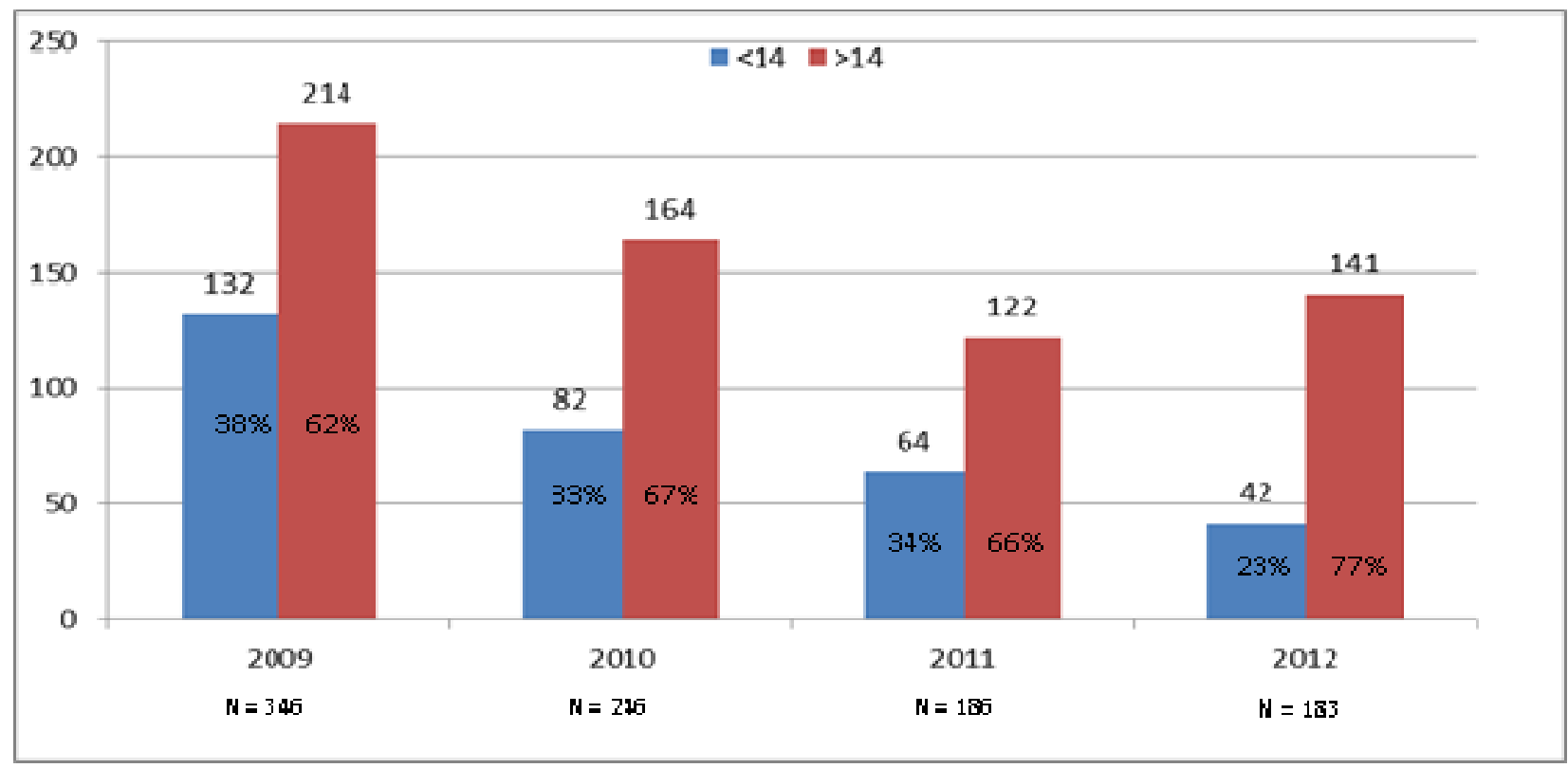

Figure 4: Dengue deaths for 2009 - 2012 by age (paediatric and adult)

Source, Epidemiology Unit, Ministry of Health

LRH has about 73,000 admissions per year. The average number of death per year is 550 (table 11).

Table 11: $L$ RH mortality statistics

\begin{tabular}{|l|l|l|l|l|l|l|l|l|l|l|l|}
\hline & $\mathbf{2 0 0 2}$ & $\mathbf{2 0 0 3}$ & $\mathbf{2 0 0 4}$ & $\mathbf{2 0 0 5}$ & $\mathbf{2 0 0 6}$ & $\mathbf{2 0 0 7}$ & $\mathbf{2 0 0 8}$ & $\mathbf{2 0 0 9}$ & $\mathbf{2 0 1 0}$ & $\mathbf{2 0 1 1}$ & $\mathbf{2 0 1 2}$ \\
\hline Total admissions & 72,552 & 64,944 & 73,554 & 69,399 & 62,201 & 66,831 & 69,647 & 83,127 & 85,986 & 83,127 & \\
\hline $\begin{array}{l}\text { Total hospital } \\
\text { deaths }\end{array}$ & 575 & 487 & 516 & 475 & 459 & 540 & 617 & 613 & 613 & 613 & 527 \\
\hline $\begin{array}{l}\text { Deaths within } \\
\text { 24hrs }\end{array}$ & 163 & 133 & 150 & 169 & 181 & 163 & 111 & 111 & 105 & 111 & 92 \\
\hline $\begin{array}{l}\text { \% deaths within } \\
\text { 24 hrs / total } \\
\text { deaths }\end{array}$ & $28.3 \%$ & $27.3 \%$ & $29 \%$ & $35.5 \%$ & $39.4 \%$ & $30.1 \%$ & $17.9 \%$ & $18.1 \%$ & $17.1 \%$ & $18.1 \%$ & \\
\hline $\begin{array}{l}\% \text { Deaths within } \\
\text { 24 hrs / total } \\
\text { admissions }\end{array}$ & $0.22 \%$ & $0.20 \%$ & $0.20 \%$ & $0.24 \%$ & $0.29 \%$ & $0.24 \%$ & $0.16 \%$ & $0.13 \%$ & $0.12 \%$ & $0.13 \%$ \\
\hline $\begin{array}{l}\% \text { total no of } \\
\text { deaths/ total } \\
\text { admissions }\end{array}$ & $0.79 \%$ & $0.74 \%$ & $0.70 \%$ & $0.68 \%$ & $0.73 \%$ & $0.80 \%$ & $0.88 \%$ & $0.73 \%$ & $0.71 \%$ & $0.73 \%$ & \\
\hline $\begin{array}{l}\text { Deaths on } \\
\text { admission }\end{array}$ & $\mathrm{X}$ & $\mathrm{X}$ & $\mathrm{X}$ & 51 & 52 & 44 & 33 & 33 & 33 & 33 & 24 \\
\hline Total admissions & 72,552 & 64,944 & 73,554 & 69,399 & 62,201 & 66,831 & 69,647 & 83,127 & 85,986 & 83,127 & \\
\hline
\end{tabular}

It is interesting to note that deaths within 24 hours, per 1000 admissions, per year, have reduced significantly from 2008 onwards (Figure 5). This is because of the improved quality of care, provided at the LRH. However the total number of deaths, per 1000 admissions, per year has not changed significantly (Figure 6). 


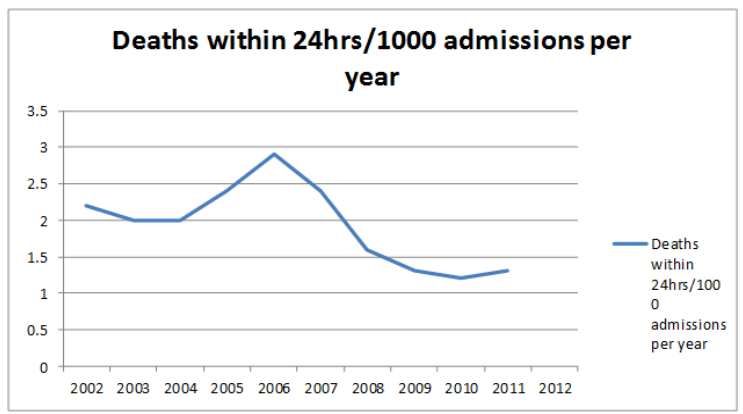

Figure 5

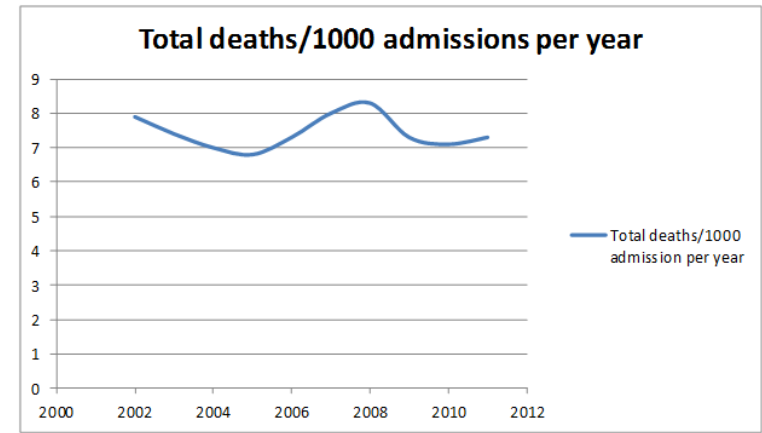

Figure 6

It is important to note that there are significant numbers of deaths on admission. This reflects the failure of identifying very sick children in the community by primary care doctors, either in the government sector or in the private sector, resulting in delayed initiation of appropriate emergency treatment and timely referral.

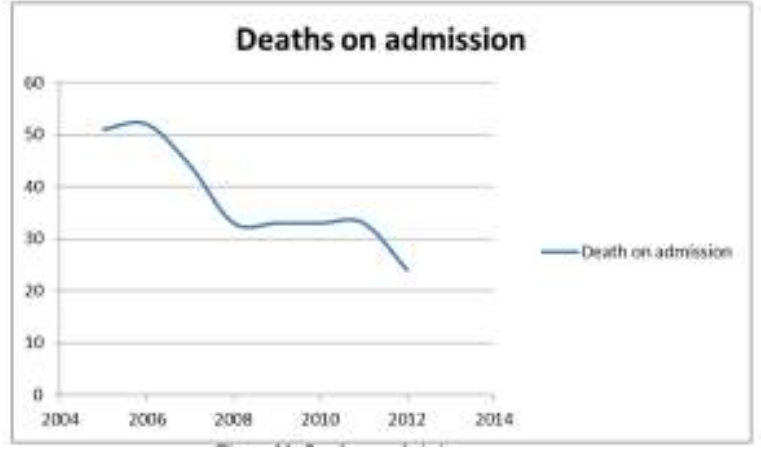

Figure 10

When considering these facts, to improve the childhood mortality rates, the strategies should be carefully planned and implemented both at community level and at institutional level. At community level, both preventive health staff and the General Practitioners should be trained for early identification of an ill child, initiation of emergency treatment, and timely referral. At hospital level, establishment of accident and emergency (A \& E) unit / primary care unit (PCU) in base hospital upwards, improving the knowledge and skills of first responders of ill children, establishing "Medical Emergency Teams" in the hospitals will have a major impact. At Teaching Hospitals and District General Hospitals, strategies should be to make more high dependency and intensive care beds available and to establish proper retrieval teams.

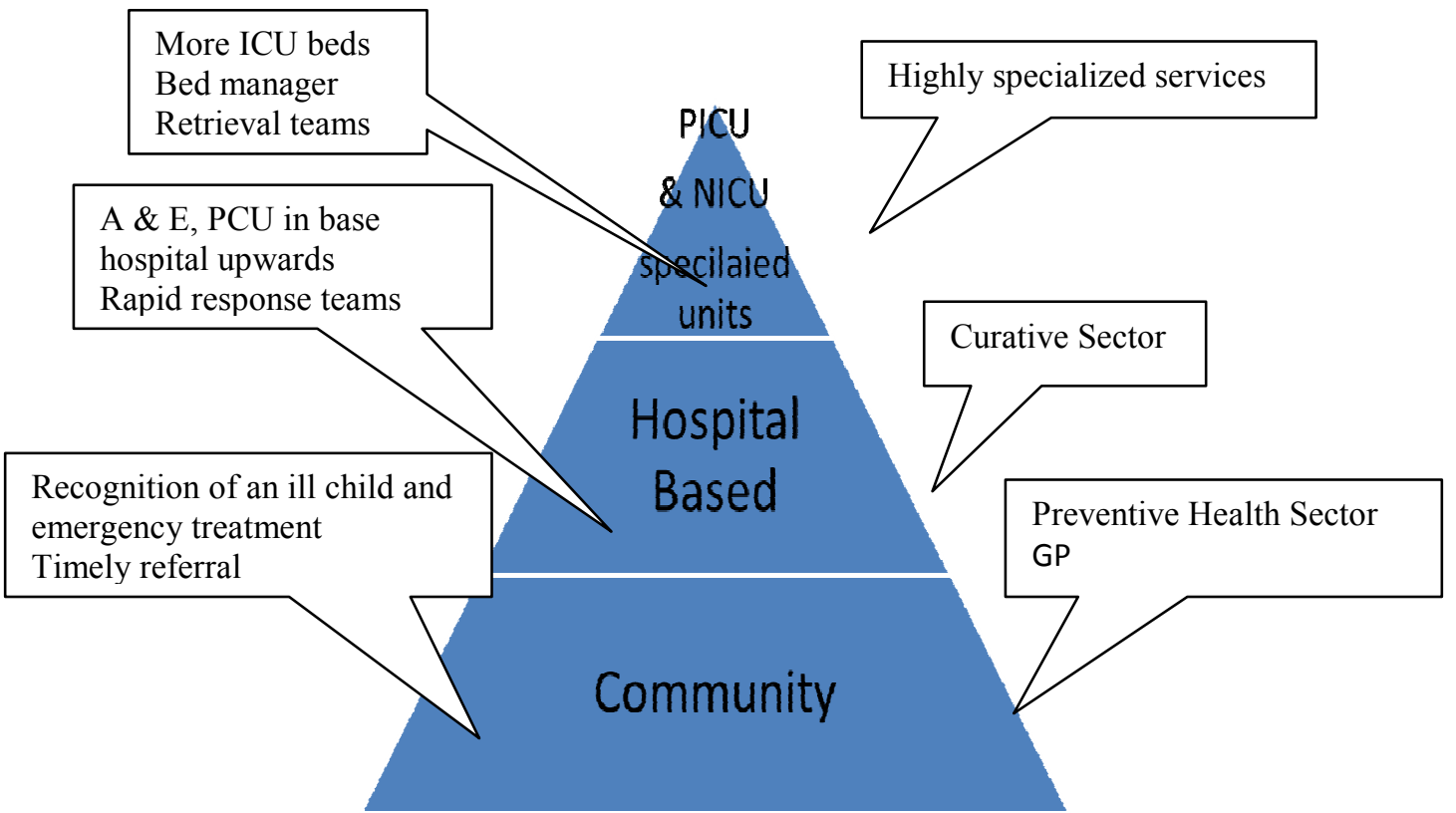

Figure 11: Strategies which should be implemented 
Let us consider the strategies at institutional Level in detail.

\section{Establish $A \& E$ and $P C U$ in hospitals}

When we were junior doctors, there were no accident and emergency departments in our hospitals; as a result, there were long delays in attending to critically ill patients. Having identified this problem, the Ministry of Health has taken the steps to establish $\mathrm{A} \& \mathrm{E}$ and PCUs in major hospitals during the last few years. However, the only fully established A\&E is at Teaching Hospital Karapitiya. When a patient comes to $\mathrm{A} \& \mathrm{E}$, triage nurses categorize the child according to the severity of the illness. The patients who need urgent resuscitation including cardio-respiratory support are referred to the "resuscitation bay". The patients who need emergency management are referred to emergency treatment unit (ETU) and the rest of the patients are referred to short stay observation units where the need for the admission is decided. Except in TH Karapitiya, there are no consultants appointed as A \& E consultants. Very often, there is a physician in charge of the A\&E, in addition to his/her duties as a ward consultant. Because of this, most of the time the ETU MOs have inadequate supervision. Unfortunately these MOs were never exposed to a structured training programme in managing critically ill patients. Having recognized this problem, the Postgraduate Institute of Medicine has identified Emergency Medicine as a specialty, with the full blessings of the Ministry of Health and an MD Emergency Medicine course would be started in February by the Multidisciplinary Board of Study, where I am functioning as the secretary at present. The trainees who qualify in MD Emergency Medicine will be appointed as Emergency Medicine Consultants after 6 years of training. A\&E or the PCU is the first contact of the critically ill patient with the hospital. Vital time is lost if the ETU staff members are not competent and updated with the appropriate knowledge and skills of managing critically ill patients. Treating a seriously ill child in the A\&E is a team work task, with different members having different roles which are smoothly coordinated by the team leader. It is like formula one racing car training and practice.

Each member is well aware of his/her own role and the target is achieved within the shortest possible time period. The team should realize the importance of team work and they should appreciate that individual skill and competencies alone are not enough. So the idea is to make a team of champions rather than a champion in a team.

\section{Improve knowledge and skills of management of very sick children among paediatric care givers}

Almost all the trainees who returned after overseas training stressed the need to introduce structured modules related to emergency paediatrics like advanced paediatric life support (APLS) and NLS to this country. Even though they were exposed to critically ill children during their local training they were of the opinion that they were lacking the training to handle critically ill children in a structured manner till they had their overseas training.

Attempts to introduce the APLS module, which teaches the structured approach to a seriously ill child, were made in 2005 by Dr. Dayananda Bandara. Unfortunately it did not succeed due to the civil war in our country. In 2007 I met Dr. Jeramy Rafftos, then the President APLS of Australia and New Zealand. He promised to give us the fullest support to establish APLS courses in Sri Lanka. As it was not possible at that time for the Australian faculty to conduct the APLS course in Sri Lanka, I was given the opportunity together with Dr. Mudiyanse, to get trained in Australia to teach APLS. This was organized by Dr. Jeremy Rafftos and the Australian APLS society was kind enough to bear the cost of this training. Following the end of the war, I managed to organize the first APLS course by the Australian team in 2010. It was a huge task to undertake. Prof Deepthi Samarage, the President of the Health Sector Development Project (HSDP) allocated money for us to buy the manikins and equipment. The UNICEF was the main sponsor of the event. Since then the Australian APLS team has been visiting Sri Lanka annually conducting one provider course and one instructor course each year. Up to now 4 provider courses have been conducted by the Australian team where 60 paediatricians were trained. I was happy to see the enthusiasm of our paediatricians to get this training spending a course fee of Rs 25,000. This year too Australian APLS course would be held in Jaffna in late February.

Evaluation after the first APLS course in 2010 showed that participants were satisfied and appreciated the course thoroughly. The letter of appreciation given to the SLCP jointly by the participants included the following comment. "As participants, we felt that all the paediatricians, postgraduate paediatric trainees and medical officers working in paediatric A\&E treatment units should participate in such courses to reduce the mortality of children presenting with life- threatening illness". 
The Australian team also trained 30 paediatricians as instructors. Most of them have been given an opportunity to teach APLS in Australia as they were up to international standard. With the help of trained local instructors we have conducted 12 local APLS courses up to now. These were three full day workshops. Nearly $50 \%$ of participants were medical officers (MOs) from different specialties including ETU, ICU and anaesthesia. The rest were paediatric and critical care trainees. It is encouraging to note that over $90 \%$ of participants, rated the course as very good and excellent and $90 \%$ of candidates have said that they have acquired $75-100 \%$ new knowledge and skills on completion of the course. This was very rewarding to the enthusiastic instructors. Interestingly, $90 \%$ of participants have not been exposed to this type of course before. This shows a notable deficiency in our healthcare system, where the majority of the doctors attend to seriously ill children without being exposed to any structured resuscitation course. In developed countries, it has been made compulsory to follow the course every 4 years. The objective is to make sure that the children are safe in the hands of these doctors.

Quite a high majority of the participants of the local course thought the course would be very useful for ETU/A\&E/PCU doctors. If we look at the LRH statistics again there is a significant number of deaths due to failed resuscitation in the ETU. As this was a very serious issue as far as the hospital is concerned, I was given the task of improving the ETU by the director. I realized that the reasons for the deaths due to failed resuscitation in the ETU are inability to identify seriously ill children, improper stabilization in the ETU, and lack of adequate knowledge and skills of the ETU staff to resuscitate and manage a seriously ill child perhaps due to the fact that they were never exposed to a structured training programme on resuscitation. Therefore, I made it compulsory for all ETU doctors to participate in the APLS programme at a concessionary rate. Here I appreciate the support given by our enthusiastic Director, Dr. Ratnasiri Hewage and the energetic Health Education Officer of LRH, Dr. Athula Wijesingha. Up to now, almost all LRH ETU doctors were trained in APLS. It is extremely rewarding to see that the impact of this training is clearly visible when comparing the deaths in the ETU due to failed resuscitation in 2011 and 2012. Sixteen deaths in 2011 have been reduced to just 5 in 2012 .

\section{Introduce the concept of rapid response team (RRT) or medical emergency team (MET)}

The way forward is to establish MET or RRT in hospitals. In 2002, the patient safety committee of Royal Children Hospital in Melbourne identified unexpected cardiac arrests in the wards which were predictable. They realized that many of these were preventable, and to overcome this problem an MET team was established. The MET team consists of a team of doctors and nurses who are well trained and able to handle emergencies. On activation by the doctors or nurses, they should respond immediately to any ward to manage medical and surgical emergencies and liaise with the intensive care unit. The objective of MET is to prevent unexpected but predictable cardiac arrests in the wards predicted by deteriorating signs and symptoms and prevented by early vigorous treatment by expertise available elsewhere in the hospital. In the developed countries MET has made a huge impact on the outcome of seriously ill children. There was a dramatic reduction of child mortality in Royal Children Hospital in Melbourne after the introduction of MET team in 2002.

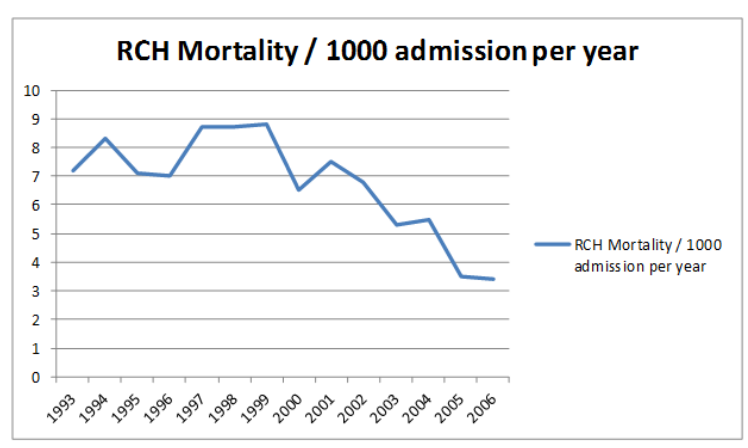

Figure 12: RCH mortality per 1000 admissions per year

I personally feel that by the introduction of the RRT or MRT concept to LRH, we should be able to reduce the total deaths per 1000 admissions per year further down which has been static for the last 10 years. However, establishing MET will not be an easy task as there are barriers. Some of these are high degree of ego, fear of criticism, and reluctance to change the behaviour and attitudes. The duties of the MET team are different to that of code blue team. The MET team stabilizes the patient before the arrest, whereas the code blue team is called when life threatening situations such as cardio-respiratory arrests occur. 
4. Establish proper retrieval system \& more intensive care beds made available

At present it is the responsibility of the referring hospital to transfer the newborns and children to the receiving hospital. This is a significant problem, as we see transport related problems from time to time which contribute significantly to transport related morbidity and mortality. Therefore, as in developed countries we need to introduce the retrieval system. I am happy to say that the Emirates Foundation of Dubai has already agreed to donate a dedicated ambulance to initiate this activity at LRH. Ministry of Health has given the approval for this project. When a peripheral hospital consultant decides to transfer a patient to a tertiary hospital for ICU care I do not have to elaborate how much precious time is wasted in trying to get an ICU bed. This is in addition to the time taken to stabilize the critically ill patient. Some of the ICU beds are not fully utilized. The Ministry should ensure that all ICUs should utilize their bed capacity to the maximum. Appointing a bed manager can be a solution for this problem.

\section{Concept of clinical governance: Clinical audit, conducting confidential inquiries into deaths \& risk management}

Concept of clinical governance includes education \& training, clinical audits, clinical effectiveness, research and development, openness and risk management.

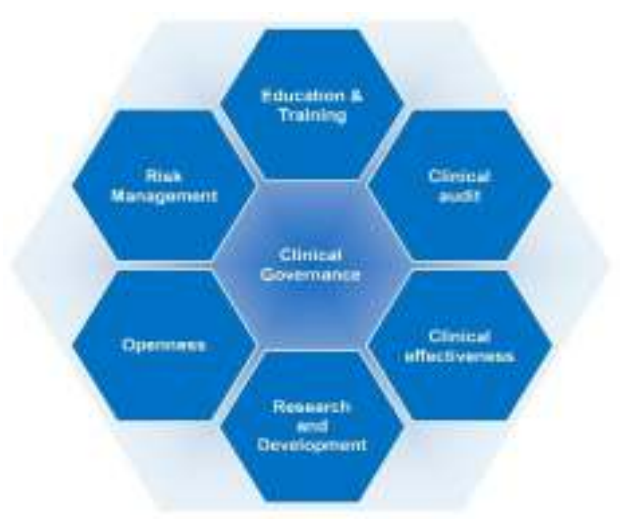

Figure 13: Framework for clinical governance

Clinical audit is to identify strategies to improve the deficiencies. Risk management is to identify the omissions that might be detrimental to the patient and take appropriate actions to correct them. Unfortunately, we have not developed the culture of doing clinical audits. This should happen in each unit at hospital level and important decisions should be conveyed to the Colleges to develop appropriate strategies to improve the outcome and to advise the Ministry for implementation. Health authorities, who conduct confidential inquiries, violate some basic principles creating unpleasantness and concerns among caregivers. Such patterns prevent achievement of the desired outcome. The respective Colleges should take leadership in conducting clinical audits, confidential inquiries and risk management in order to have a better outcome.

\section{Role of Advocacy of paediatricians}

Most of the senior paediatricians concentrate mostly on clinical work forgetting the responsibility of the advocacy role and to advice the government on the strategies to improve the childcare which will have a major impact on national indices. It is important to note that when ineffective strategies are implemented by some stakeholders, it is a waste of money of the government and donor agencies. Therefore, paediatricians should be proactive in studying the disease trends and promote appropriate management and preventive strategies of national significance.

Plan for 2013

During this year, I would mainly concentrate on CPD programmes by:

- Intensifying the current CPD Programmes

- Reducing case fatality rate of dengue from $0.4 \%$ to $0.1 \%$

- Introducing PEM module and "simulation concept" to CPD programme.

- Organizing annual session / Commonwealth paediatric gastroenterology and nutrition association

- Strengthening the recording of data / statistics

- Introducing the concept of clinical auditing

- Inaugural Dr. Stella de Silva oration - we will be honouring the yeoman services of an eminent paediatrician and a great teacher who departed from us last year. Dr. Stella de Silva inaugural scientific oration will be held along with the annual scientific sessions of the college in memory of her.

\section{Simulation based education-}

Training using simulators is the latest strategy used to train healthcare workers to achieve necessary skills ensuring patient safety in developed countries. That means the procedures can be practised using simulators without causing harm to real patients in order to minimize first failed attempts and minimize adverse events subsequent to the procedures. This is exactly what is mentioned in the Hippocrates Oath. "I will prescribe regiment for the good of my patients according to my ability and judgment and do no harm to anyone. 
Effectiveness of simulator based education is by improving:

1. Self-efficacy (improvement in learner's selfconfidence)

2. Competency (skill improvement in simulation settings)

3. Operational performance (skill improvement in clinical settings)

4. Improved outcome (improvement in patient outcome)

At the end of the simulation based training the participant will learn:

- Leadership

- Teamwork

- Clear communication

- Decision making and conflict resolution

- Clinical assessment

- Clinical skills acquisition

- Equipment management

- Role clarity

\section{Why are CPD programmes important?}

To pass both undergraduate and postgraduate exams only $50 \%$ marks are required. The question is, how are we learning the balance $50 \%$ ? The medical officers acquire the balance $50 \%$ of the knowledge and skills during their training period under the supervision of consultants. Unfortunately, the consultants, after the postgraduate exams are not under supervision. Therefore, it is essential for the consultants to update their knowledge and skills by attending regularly to CPD programmes. In the developed countries certificates of attending these CPD programmes are mandatory and a target number of points should be achieved for the renewal of medical council registration. The conventional CPD programmes like lectures, will improve the diagnostic skills and therapeutic skills. But these will not improve and test the technical skills like structured approach and procedural skills and non-technical skills like attitude, team work and behaviour. However, the present CPD programmes, like APLS and NLS address all these issues. These time-tested modules are well in place in developed countries to achieve the above skills by the participants at the end of the day.

It is important to note that adult learning is different to that of children and the resource persons of the CPD programmes should be aware of this.

The Millers pyramid gives the concept of adult learning of skills ${ }^{13}$.

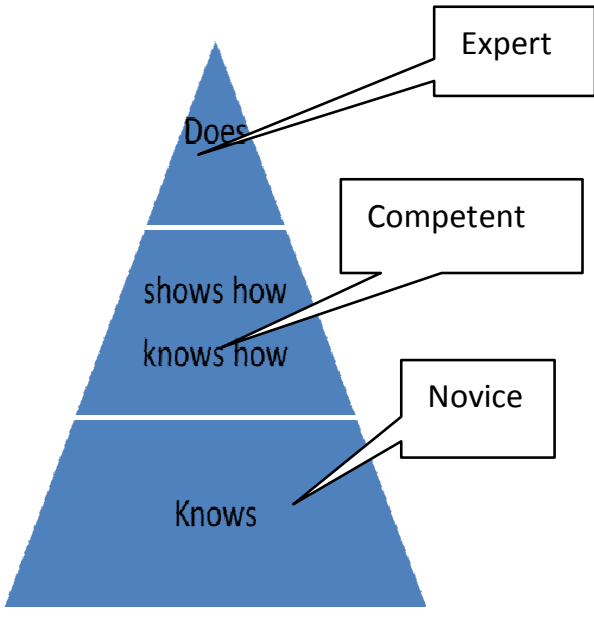

Figure 14: Miller's pyramid

According to Kirkpatrick's hierarchy of programme evaluation $^{14}$ at the end of the programme the participants will be satisfied with the knowledge and the skills they acquire which will change their behaviour and as a result of that it will have an impact on the society.

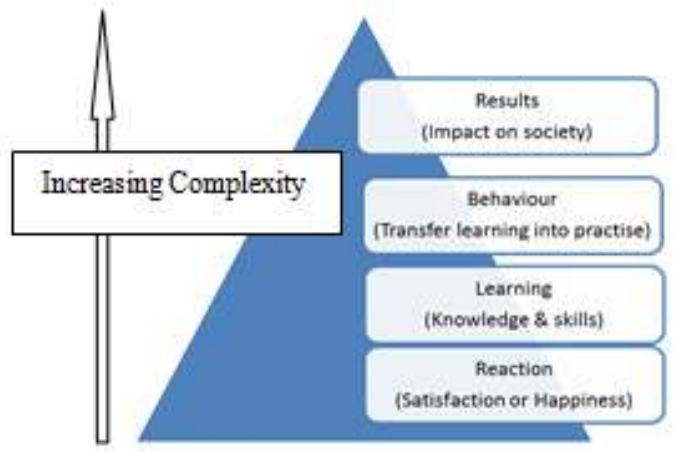

Figure 15: Level of Programme evaluation

The reduction of deaths due birth asphyxia following NLS and reduction of failed resuscitation in the ETU/LRH following APLS and reduction of dengue deaths after dengue training programmes are examples of the impact of new knowledge on the society.

According to the report of the external review of maternal and newborn in Sri Lanka, in 2007 October $^{15}$, there are issues related to the present inservice training conducted by FHB.

- They are conducted in Ad hoc manner

- There is no consolidated training plan

- There is no synchronization or coordination at central level

- The master training programmes do not appear to work well 
- There is no monitoring, or evaluation of the quality of training

However, there are constraints to implement successful CPD programmes.

- CPD programmes are not mandatory in our country

- There is no structured mechanism at present

- There is no budget allocated or only limited budget is available

- The process of obtaining duty leave sometimes is an issue

CPD programmes should be conducted by people who have the clinical and application authority in that field basically by respective colleges and societies. It has been observed that when these modules are conducted by authorities without any clinical background, one might not get the desired results. Therefore, as paediatricians, it is our duty to teach the paediatric caregivers to update their knowledge utilizing funds of the donor agencies or the Ministry of Health effectively.

I would like to wind up reminding you three quotations regarding knowledge.

- The greatest obstacle to discovery is not ignorance - it is the illusion of knowledge (Janiel J Boorstin)

- Knowledge has to be improved, challenged and increased constantly or it vanishes (Peter Druder)

- An investment in knowledge always pays the best interest! (Benjamin Franklin)

\section{References}

1. Duke T. Child Health in a Global Context. In: South M., Isaacs D, editors, Practical Paediatrics 7th ed. London; Churchill Livingstone Elsevier: 2012.15-21

2. Department of Census and Statistics. Income and Expenditure Survey 2009/10. Colombo: Department of Census and Statistics; 2011.

3. UNICEF. Water, sanitation and Hygiene; 2011. Available from: http://www.unicef.org/wash/index_statistics.html

4. Department of census and statistics. Sri Lanka Demographic and Health Survey 2006/07. Colombo: Department of census and statistics; 2009.
5. Registrar Generals Department. Vital Statistics; 2011. Available from: http://www.rgd.gov.lk

6. Family Health Bureau. Annual Report on Family Health. Colombo: Ministry of Health; 2010.

7. World Health Organisation Regional Office for South East Asia. Health-related Millennium Development Goals 2012. Available from: http://www.searo.who.int/entity/health situationt rends/documents/MDG_Brochure 2012.pdf

8. Rajaratnam JK, Marcus JR, et al. Neonatal, postneonatal, childhood and under-5 mortality for 187 countries, 1970-2010: a systematic analysis of progress towards Millennium Development Goal 4. Lancet 2010; 375(9730): 1988-2008. http://dx.doi.org/10.1016/S0140-6736(10)60703-9

9. Medical Statistics Unit,. Unpublished data

10. Darmstadt GL, Bhutta ZA, et al. Evidence-based, cost-effective interventions: how many newborn babies can we save? Lancet 2005; 365(9463): 977-88. http://dx.doi.org/10.1016/S0140-6736(05)71088-6

11. Mugford M, Piercy J, Chalmers I. Cost implications of different approaches to the prevention of respiratory distress syndrome Archives of Disease in Childhood 1991; 66: 75764.

http://dx.doi.org/10.1136/adc.66.7_Spec_No.757

12. Tubman TRJ, Halliday HL, Normand C. Cost of surfactant replacement treatment for severe neonatal respiratory distress syndrome: a randomized controlled trial. British Medical Journal 1990; 301(6756): 842-5. http://dx.doi.org/10.1136/bmj.301.6756.842

13. Miller's Pyramid: Available from: http://www.simbase.co/results/impactassessment-model/current-state-of-impactassessment/874-2/

14. Faculty of Medicine, Dentistry and Health Sciences. How to evaluate \& the evaluation cycle. Available from:

http://www.meddent.uwa.edu.au/teaching/faculty -evaluation/evaluation-cycle

15. Ministry of Health Care and Nutrition, World Health Organization. Report of the external review of maternal and newborn health. Colombo, Sri Lanka: WHO; 2007 